\title{
The Ambivalence of the Barley Mlo Locus: Mutations Conferring Resistance Against Powdery Mildew (Blumeria graminis f. sp. hordei) Enhance Susceptibility to the Rice Blast Fungus Magnaporthe grisea
}

\author{
Birgit Jarosch, Karl-Heinz Kogel, and Ulrich Schaffrath \\ Institut für Phytopathologie und Angewandte Zoologie, Justus-Liebig-Universität Giessen, Ludwigstr. 23, \\ D-35390 Giessen, Germany \\ Accepted 1 February 1999.
}

\begin{abstract}
Recessive alleles of the barley Mlo locus confer non-racespecific resistance against the powdery mildew fungus Blumeria graminis f. sp. hordei (Bgh). Recently the Mlo gene has been isolated and it was suggested that the Mlo product is a negative regulator of cell death. Thus, loss of function can precondition cells to a higher responsiveness for the onset of multiple defense functions. Here, we document an enhanced susceptibility of barley mlo mutants to the rice blast fungus Magnaporthe grisea. The disease phenotype is independent of the barley cultivar in which the mlo allele has been introgressed and occurs in equal amounts in barley backcross lines of cv. Ingrid carrying the mlo-1, mlo-3, or mlo-5 allele. Ror genes, which are required for the full expression of $m l o$ resistance in barley against $B g h$, do not affect the specific $m l o$-mediated phenotype observed after $M$. grisea infection. Formation of an effective papilla restricts blast development in epidermal cells of Mlo plants. In contrast, papillae are mostly penetrated in mlo mutants and, as a consequence, the fungus spreads into adjacent mesophyll cells. Both wild-type plants and mlo mutants did not differ in perception of a purified elicitor derived from $M$. grisea. Thus, we hypothesize that a functional Mlo protein is a prerequisite for penetration resistance of barley to fungal pathogens like $M$. grisea. The benefit of $m l o$ alleles for durable resistance in barley and a proposed role of mlo-type-mutations in rice are discussed.
\end{abstract}

Among monocots, powdery mildew is one of the most destructive diseases. In barley, the disease is caused by the obligate biotrophic fungus Blumeria graminis f. sp. hordei (Bgh; formerly known as Erysiphe graminis f. sp. hordei). Resistance of barley to the pathogen operates on several levels of specificity. A full range of dominant or partially dominant inherited resistance genes have been characterized (Wiberg 1974) and shown to depend on the gene-for-gene concept

Corresponding author: K.-H. Kogel; Telephone: +49 64199 37491; Fax: +49 64199 37499; E-mail: Karl-Heinz.Kogel@ agrar.uni-giessen.de

Present address of Ulrich Schaffrath: Institut für Biologie III, RWTH Aachen, Worringer Weg 1, D-52074 Aachen, Germany.
(Flor 1971). Other cultivars have quantitative resistance that is at least partly under polygenic control (Jones et al. 1982). An additional type of disease resistance in barley is provided by the mlo alleles (Jørgensen 1994).

The resistance trait conferred by mlo is recessively propagated and non-race-specific since it is effective against all isolates of Bgh (Jørgensen and Mortensen 1977; Brown and Jørgensen 1991; Lyngkjaer et al. 1995). A characteristic feature of all mlo mutants is the spontaneous occurrence of lesions on the leaf surface that is a true pleiotropic effect of the mlo alleles (Jørgensen 1992). For that reason, mlo plants can be categorized with other lesion-mimic mutations such as acd (accelerated cell death) and $l s d$ (lesions simulating disease) in Arabidopsis and the $l l s$ (lethal leaf spot) mutation in maize, all of which seem to be altered in the induction of cell death (Dangl et al. 1996). Recently, the Mlo gene of barley has been isolated and the deduced protein was predicted to be membrane associated. It was hypothesized that, in the absence of the Mlo protein, plants will be primed for the onset of multiple defense functions (Büschges et al. 1997). Breeding with mlo resistance has led to a considerable number of commercial spring barley varieties combining a moderate lesion type with extended yield capacity (Jørgensen 1992).

Our goal was to examine the Mlo function in barley after inoculation with Magnaporthe grisea (Hebert) Barr (anamorph, Pyricularia grisea (Cooke) Sacc., formerly P. oryzae Cavara) (Rossman et al. 1990). M. grisea is the causal agent of the rice blast disease, one of the most devastating crop diseases worldwide (Ou 1980). Breeding for resistance to this fungus is difficult and durability of new resistance genes under field conditions is very poor (Hamer et al. 1993). The fungus can be easily isolated from lesions of various hosts, the majority of which are monocotyledonous plants like wheat, barley, maize, goosegrass (Eleusine indica (L.) Gaertn.), and weeping-lovegrass (Eragrostis curvula (Schrad.) Nees) (Heath et al. 1991; Valent and Chumley 1991; Hamer et al. 1993), and some untypical hosts such as Commelina spp. (Purchino and Muchovej 1993). However, all isolates clearly represent a single species (Hamer et al. 1993).

The mechanism of pathogenesis of $M$. grisea on rice includes elaboration of an appressorium that supports direct penetration through the cuticle of the host plant (Valent and 
Chumley 1991). So far, natural infections of barley with $M$. grisea have not been recorded. Nevertheless, M. grisea can infect barley under favorable laboratory conditions (Sweigard et al. 1998). To our knowledge, no form of resistance of barley to $M$. grisea has been documented. Here, we report on the infection process of different $M$. grisea races on barley plants carrying the Mlo wild-type gene or one of several mlo alleles.

\section{RESULTS}

Inoculation of barley cv. Ingrid (Mlo) with Magnaporthe grisea race 007 resulted in disease symptoms that were visible on the leaf surface after 5 to 7 days (Fig. 1A). Lesions were composed of a gray center surrounded by a brownish ring of necrotic cells and were therefore typical for blast. We addressed the question as to whether genes conferring resistance to powdery mildew have an effect on the development of $M$. grisea. A random screening of the infection phenotypes of barley cv. Ingrid (Mlo) and Ingrid backcross lines (BCIngrid) carrying the different powdery mildew resistance genes $\mathrm{Mlg}$, Mla-12, and mlo-5, respectively, was carried out after inoculation with $M$. grisea race 007 . Unexpectedly, only plants of the mlo-5 genotype were highly susceptible to rice blast whereas the other backcross lines showed very slight symptoms and did not differ between each other (Fig. 1C). To exclude the possibility that susceptibility to $M$. grisea is specifically based on the function of the mlo-5 allele of the Mlo locus, we inoculated barley backcross lines of cv. Ingrid carrying the $m l o-1$ or $m l o-3$ allele with $M$. grisea race 007 (Fig. 1A). Without exception, leaves of all mlo mutants were highly susceptible and became covered with blast symptoms including necrotic tips. In contrast, leaf tips of Mlo wild-type plants looked healthy and only a few symptoms were observed on the leaf surface. These findings strongly suggest that enhanced susceptibility of barley to M. grisea is dependent on a loss of function of the Mlo gene product. Similar results were obtained after inoculation of these barley lines with race 031 of M. grisea (Fig. 1B). In a further experiment, we addressed the question as to whether the genetic background might affect mlo-mediated susceptibility of barley against $M$. grisea. Therefore, we inoculated cv. Pallas (Mlo) and an mlo-5 backcross line of Pallas with races 007 and 031 of M. grisea. Pallas showed very few blast symptoms, whereas the mloresistant backcross line was strongly infected by both races (data not shown).

Recently, genes have been identified that control mlomediated resistance in barley. Loss of function of these Ror (required for mlo-mediated resistance) genes results in successful infection of mlo genotypes by $B g h$ in a non-racespecific manner (Freialdenhoven et al. 1996). To test the effect of a mutation in the Ror locus on the development of rice blast, barley plants with the genotype mlo-5/rorl were inoculated with $M$. grisea race 007. Figure 1D shows that the rorl mutation did not affect the disease phenotype of barley mutant A98 (mlo-5/rorl) plants, compared with BCIngrid (mlo5/Rorl) plants, thus indicating that the Ror gene does not control barley/M. grisea interactions.

We were interested in the cytological events accompanying the enhanced blast susceptibility of mlo mutants. Figure 2 shows the results of the microscopic survey of interactions. For the evaluation we followed the method of Koga et al.
(1988, 1990). Two differentiation classes were defined: one classifies the type of penetrated epidermal cells and the other takes into account the type of resistance responses performed by the cells. Cells were grouped as (i) so-called long cells located above vascular bundles and (ii) short cells including those surrounding the stomata. Host defense responses were classified according to two criteria: (i) highly localized cell wall appositions (papillae) at sites of fungal attack; and (ii) a whole cell autofluorescence as an indicator for the hypersensitive response (HR; Görg et al. 1993; Kita et al. 1981). An interaction site was defined as a successful attempt of the fungus to invade a cell or by the onset of a visible defense response. We analyzed interaction sites in cv. Ingrid (Mlo) and BCIngrid mlo-5 $72 \mathrm{~h}$ post inoculation with $M$. grisea race 007 (Fig. 2A). On both genotypes, 1 to $5 \%$ of attacked short cells did not show any visible defense response and fungal hyphae grew unrestrictedly in these cells. On Mlo plants, about $44 \%$ of attacked cells formed an effective papilla whereas only $11 \%$ did so in the mlo-5 backcross line. These papillae were judged to be effective in that no fungal development occurred in these cells. The frequency of HR of penetrated epidermal cells was comparable (about 45\%) in both genotypes. However, in attacked cells of cv. Ingrid (Mlo) fungal hyphae were much shorter than those in mlo-5 plants, where hyphae took up the whole cells (Fig. 3). Hence, it appears as if HR in cv. Ingrid $(\mathrm{Mlo})$ is more effective at restricting fungal growth than in BCIngrid mlo-5. As an explanation, we assume that HR in cv. Ingrid (Mlo) occurs earlier or more rapidly in time to stop the fungus. A further class of cellular host responses is the concomitant occurrence of epidermal and mesophyll HR (Fig. 3B). This phenotype was found mostly on BCIngrid mlo-5 plants (44 versus $9 \%$ of interaction sites). This shows that in BCIngrid mlo-5 about half of all penetration attempts were successful, with the consequence that the infection proceeded to the mesophyll tissue. A similar distribution of cellular responses was found in the rorl mutant A89 (mlo-5/rorl) (data not shown). Analysis of interaction sites on long cells compared with short cells did not reveal qualitative differences between the genotypes in plant responses or fungal development (Fig. 2B). We addressed the question as to whether increased lesion size correlated with further development of fungal biomass. Microscopic analysis of interaction sites by $96 \mathrm{~h}$ after inoculation showed further growth of fungal hyphae penetrating several epidermal cells accompanied by an increased number of mesophyll cells undergoing HR and thus leading to larger lesions in BCIngrid mlo-5 (Table 1).

Because it appears that the mlo mutant lines are defective in the onset of effective resistance responses, we addressed the question as to whether the genotypes differ in the perception of signal molecules derived from $M$. grisea. For that purpose, we used an elicitor that has been shown to induce multiple resistance responses in rice (Schaffrath et al. 1995). Aqueous solutions of elicitor were infiltrated into the intercellular spaces of barley leaves. As a marker for the host response, peroxidase (POX) activity was measured. Enzyme activity increased in both genotypes upon infiltration with varying concentrations of elicitor, but activities showed the same dose dependency (Fig. 4). The kinetics of POX activity followed a similar pattern in cv. Ingrid (Mlo) and in the BCIngrid mlo-5 (Fig. 5). Thus, we conclude that perception of the elicitor is not altered by the mlo mutation. 

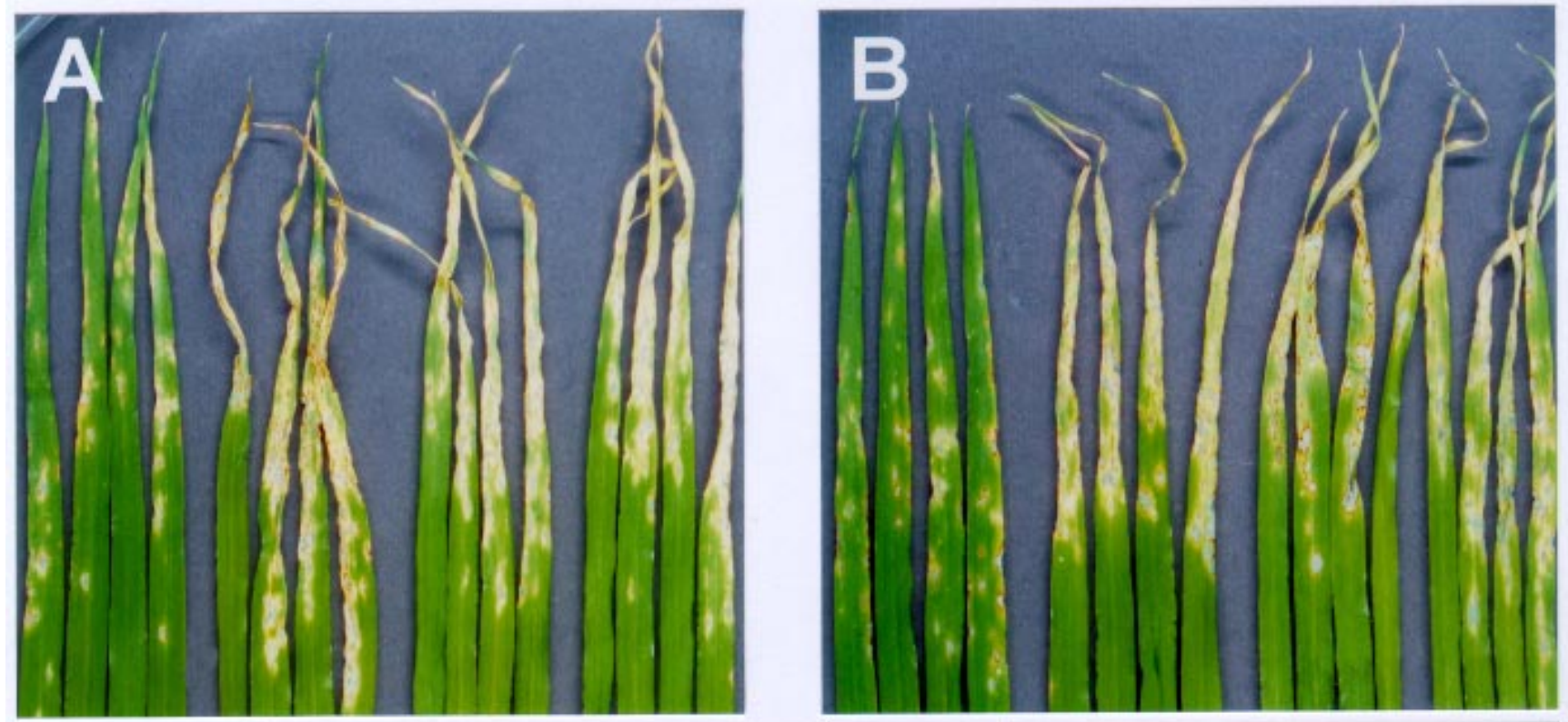

\begin{tabular}{|l|ccc|}
\hline $\begin{array}{c}\text { Ingrid } \\
(\text { Mlo })\end{array}$ & mlo-5 & $\begin{array}{c}\text { BCIngrid } \\
\text { m/o-3 }\end{array}$ & m/o-1 \\
\hline \multicolumn{3}{|c|}{ Magnaporthe grisea } & race 007 \\
\hline
\end{tabular}

\begin{tabular}{|c|ccc|}
\hline $\begin{array}{c}\text { Ingrid } \\
(\text { Mlo })\end{array}$ & mlo-5 & $\begin{array}{c}\text { BCIngrid } \\
\text { mlo-3 }\end{array}$ & mlo-1 \\
\hline \multicolumn{3}{|c|}{ Magnaporthe grisea } & race 031 \\
\hline
\end{tabular}
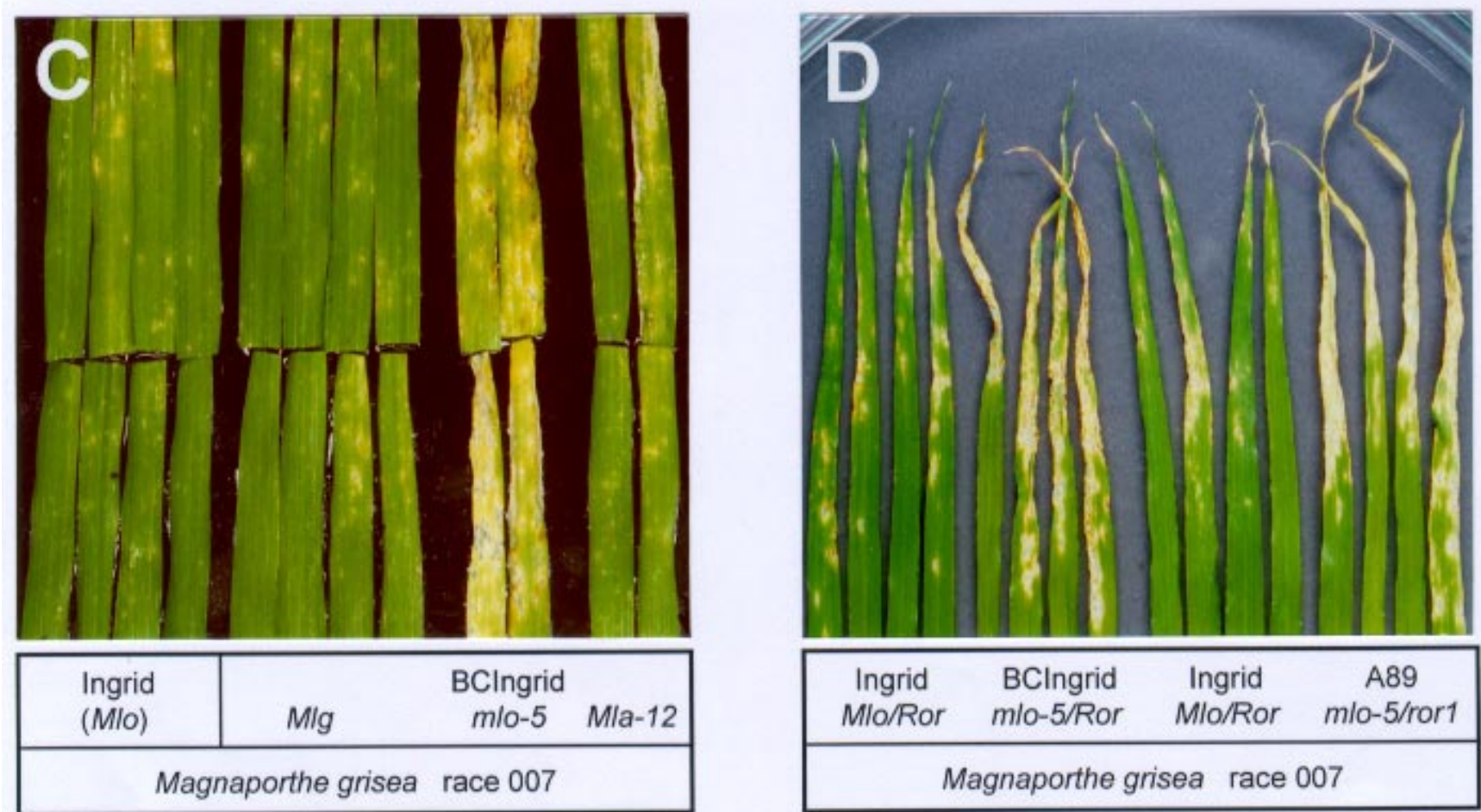

Fig. 1. Leaves from infection assays 7 days after inoculation. Barley plants of $\mathrm{cv}$. Ingrid (Mlo) and backcross lines of cv. Ingrid carrying the $m l o-1$, $m l o-$ 3, or mlo-5 allele of the Mlo locus, were inoculated with race (A) 007 or (B) 031 from Magnaporthe grisea. C, Leaves from barley plants with different powdery mildew resistance genes after infection with race 007 from $M$. grisea. D, Phenotypes of barley plants carrying different alleles of the Mlo and Rorl locus after infection with race 007 from M. grisea. The Rorl locus defines a gene that is required for mlo-mediated resistance. All experiments were performed (A, B, and $\mathbf{D})$ at least twice or $(\mathbf{C})$ in triplicate with similar results. 


\section{DISCUSSION}

The present study was basically aimed at the question as to whether mlo resistance, which is extremely effective in controlling powdery mildew in barley, might be agronomically useful for the control of the rice blast disease. We demonstrated here that such an approach probably would fail.

Unexpectedly, barley plants carrying an mlo allele for powdery mildew resistance are much more susceptible than Mlo plants to $M$. grisea. Although sporulation occurred on both Mlo and mlo genotypes, the degree of sporulation was much higher in mlo plants, which showed enlarged lesions (data not shown). It has been documented that host specificity among $M$. grisea isolates from different plant species is rather narrow for any particular isolate (Valent and Chumley 1991; Hamer et al. 1993). Therefore, the moderate number of blast symptoms on Mlo plants may be explained by the fact that races 007 and 031 are isolates from rice with unknown virulence on barley. Recent studies on pathogenicity genes with different races of $M$. grisea and other barley cultivars have revealed that, in principle, the fungus is capable of causing devastating symptoms on barley (Sweigard et al. 1998).

By using near-isogenic barley lines bearing different recessive alleles of the Mlo locus, we demonstrate unequivocally and for the first time that the Mlo locus controls the interaction of $M$. grisea and barley. An oligogenic effect has been excluded by analyzing the mlo alleles introgressed into different genetic backgrounds. Furthermore, other agronomically
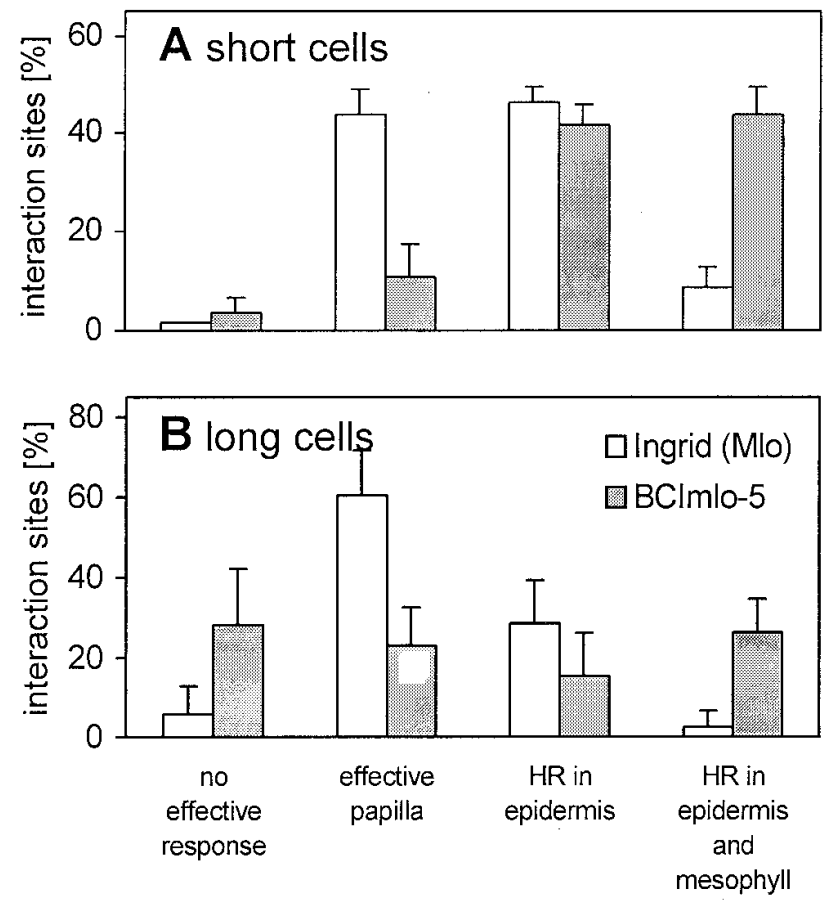

Fig. 2. Frequency of interaction sites on barley cv. Ingrid (Mlo) and the barley backcross line carrying the mlo-5 allele (BCImlo-5) of the Mlo locus infected with race 007 from Magnaporthe grisea. Leaves were harvested $72 \mathrm{~h}$ after inoculation and prepared for microscopy as described in the text. Single-cell responses were discriminated as indicated. Data from a single experiment shown are based on (A) 100 infection sites on short cells and (B) 50 infection sites on long cells from four leaves. relevant powdery mildew genes such as $M l g$ and Mla-12 do not affect blast disease development.

The infection process of $M$. grisea on barley covers a series of temporal sequences reflecting germination, successful invasion, and induction of host defense responses. Plants of the Mlo genotype counteract penetration attempts by a highly localized apposition of cell wall material. In half of all incidences the formation of a papilla was able to effectively arrest further fungal invasion of the epidermal cells. However, if the fungus penetrates into a cell (approximately $40 \%$ of interaction sites), then development of intracellular mycelium is still very poor. Limitation of fungal growth in the first invaded cell was accompanied by a strong autofluorescence of cell walls
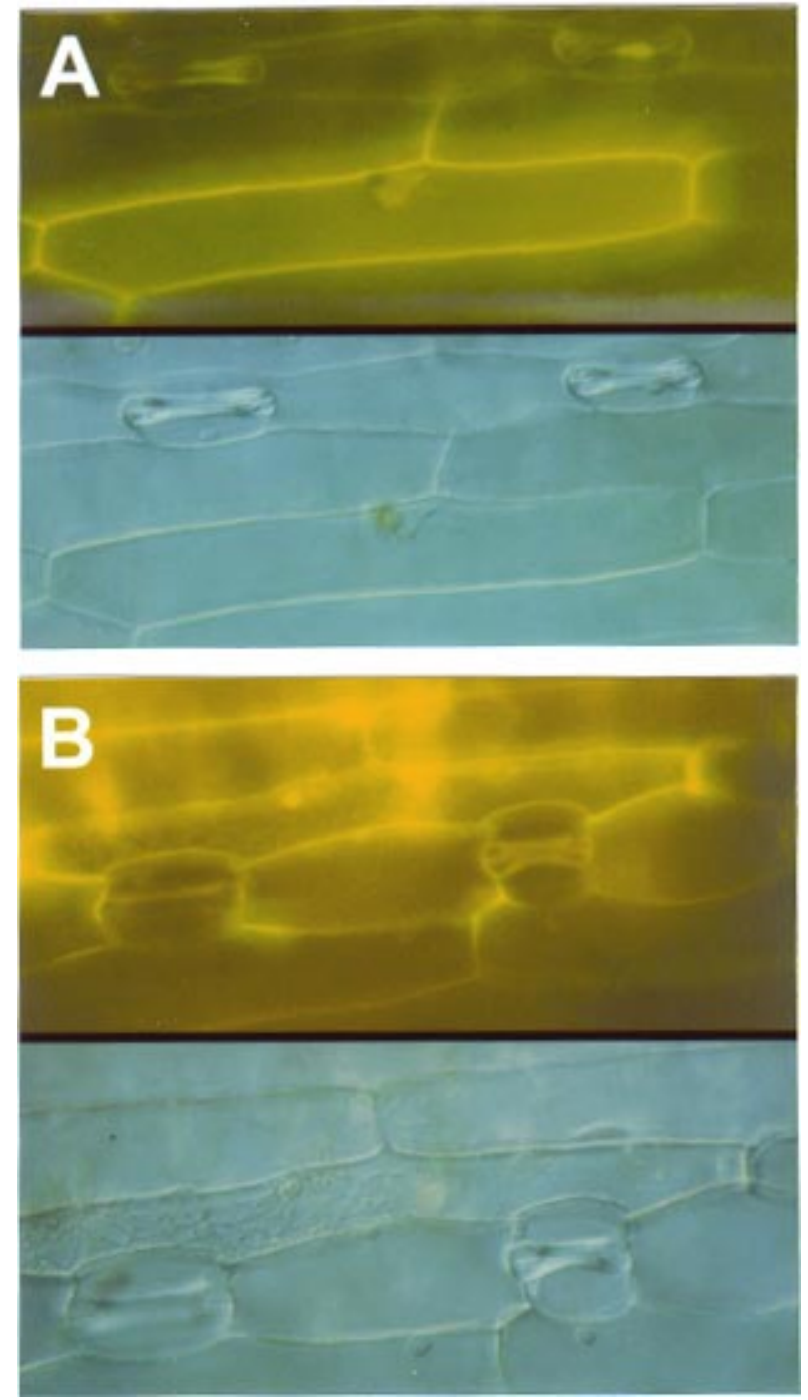

Fig. 3. Light micrographs depicting plant responses to infection with race 007 from Magnaporthe grisea in barley $72 \mathrm{~h}$ after inoculation on short cells. A, Epidermal cells of cv. Ingrid (Mlo). Illumination with UV light results in a strong autofluorescence of cell walls (indicative for hypersensitive reaction) of the penetrated cell (upper part). A short hyphae can be observed in the same cell with transmission bright light (lower part). B, Leaf of a barley backcross line of cv. Ingrid carrying the mlo-5 allele of the Mlo locus. The fungus has penetrated successfully into the first epidermal cell and has started to grow into the surrounding tissue (lower part). Under UV light (upper part) a strong autofluorescence was observed in epidermal and mesophyll cells. 
indicative for an HR (Koga et al. 1990, 1994; Peterhänsel et al. 1997). Only in less than $10 \%$ of all incidences could epidermal and mesophyll HR be observed simultaneously. This is likely due to fungal spread into neighboring cells. In these few incidences an HR does not effectively restrict fungal development and sporulation. In contrast, $M$. grisea develops undisturbed on mlo barley and in half of all interaction sites spreads into mesophyll cells. Therefore, the mlo phenotype is due to massive fungal growth rather than to expression of hypersensitivity.

These events can be more easily interpreted in the light of what is going on in the rice/rice blast interaction. For rice, it has been shown that development in the first penetrated cell is a very critical step for the outbreak of blast disease (Peng and Shishiyama 1988; Thieron 1993; Koga 1994). In incompatible interactions, fungal growth is stopped in the first attacked cell by deposition of lignin or lignin-like substances (Thieron 1993). If the fungus is not arrested, invasion proceeds into adjacent epidermal and mesophyll cells; this happens predominantly in compatible interactions (Thieron 1993). The HR usually occurs in such cells but this is probably too late to prevent disease. The HR, in this situation, was considered to be a consequence of progressive cellular destruction associated with susceptibility rather than a cause of resistance (Thieron 1993), i.e., it is probably not what is usually consid-

Table 1. Frequencies of papillae and disease symptoms on barley cv. Ingrid (Mlo) and a barley backcross line carrying the mlo-5 allele (BCIngrid mlo-5) infected with race 007 from Magnaporthe grisea $96 \mathrm{~h}$ after inoculation $^{\mathrm{a}}$

\begin{tabular}{|c|c|c|c|c|c|}
\hline \multirow[b]{3}{*}{ Barley line } & \multicolumn{5}{|c|}{ Interaction sites (\%) } \\
\hline & \multirow[b]{2}{*}{ Papillae } & \multicolumn{4}{|c|}{$\begin{array}{l}\text { Hypersensitive reaction in epidermis and } \\
\text { mesophyll (diameter of lesions, in } \mathbf{~ m m} \text { ) }\end{array}$} \\
\hline & & $<0.2$ & $<0.6$ & 0.6 to 1.2 & $>1.2$ \\
\hline Ingrid $(M l o)$ & 42.6 & 28.9 & 21.1 & 3.7 & 3.7 \\
\hline BCIngrid mlo-5 & 7.1 & 5.1 & 18.6 & 31.1 & 38.1 \\
\hline
\end{tabular}

${ }^{a}$ Papillae were evaluated with a magnification of $\times 250$ whereas the diameter of necrosis was analyzed with a magnification of $\times 100$. Data from the single experiment shown are based on evaluation of four leaves with 100 infection sites per leaf.

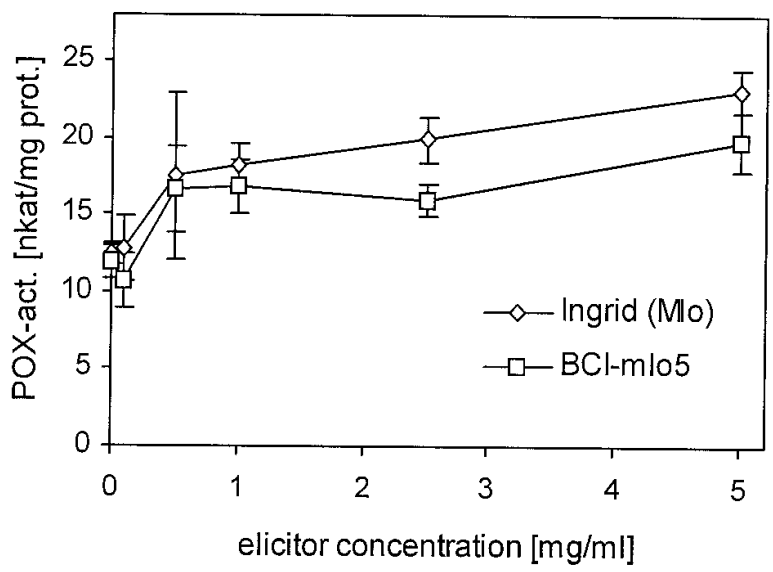

Fig. 4. Dose-response curves for the induction of peroxidase (POX) activity in barley leaves of cv. Ingrid (Mlo) and a backcross line of cv. Ingrid carrying the mlo-5 allele (BCImlo-5) treated with an elicitor from Magnaporthe grisea. Vertical bars represent SD about the mean of three samples from a representative of two independent experiments. ered to be an HR. It is a striking similarity of incompatible interactions of $M$. grisea on rice and on barley that restriction of fungal invasion depends on the efficiency of a resistance response in the first penetrated cell.

Enhanced susceptibility of mlo barley to the rice blast fungus is an outstanding phenomenon that does not support the hypothesis that mlo mutants react to diseases other than powdery mildew in the same way as non-mlo varieties (Jørgensen 1992). Furthermore, we show that the mlo mutation does not confer resistance against all other pathogens that penetrate living epidermal cells, as hypothesized by Jørgensen. Although $M$. grisea is a facultative, biotrophic fungus that is able to produce toxins and that may kill penetrated cells before colonization (Umetsu et al. 1974; Lebrun et al. 1990), our results indicate that the restriction of fungal growth is due to an active defense.

A non-race-specific elicitor derived from $M$. grisea that induces various resistance responses in rice is also active in barley. But the induction pattern of enzyme activity is similar in both Mlo wild-type plants and mlo mutants. Therefore, it seems that in the barley/rice blast interaction the perception of this signal molecules is not altered.

It was hypothesized that recessive mlo alleles similar to lesion-mimic mutants in Arabidopsis represent cell death control mutants that define wild-type genes playing a role in the

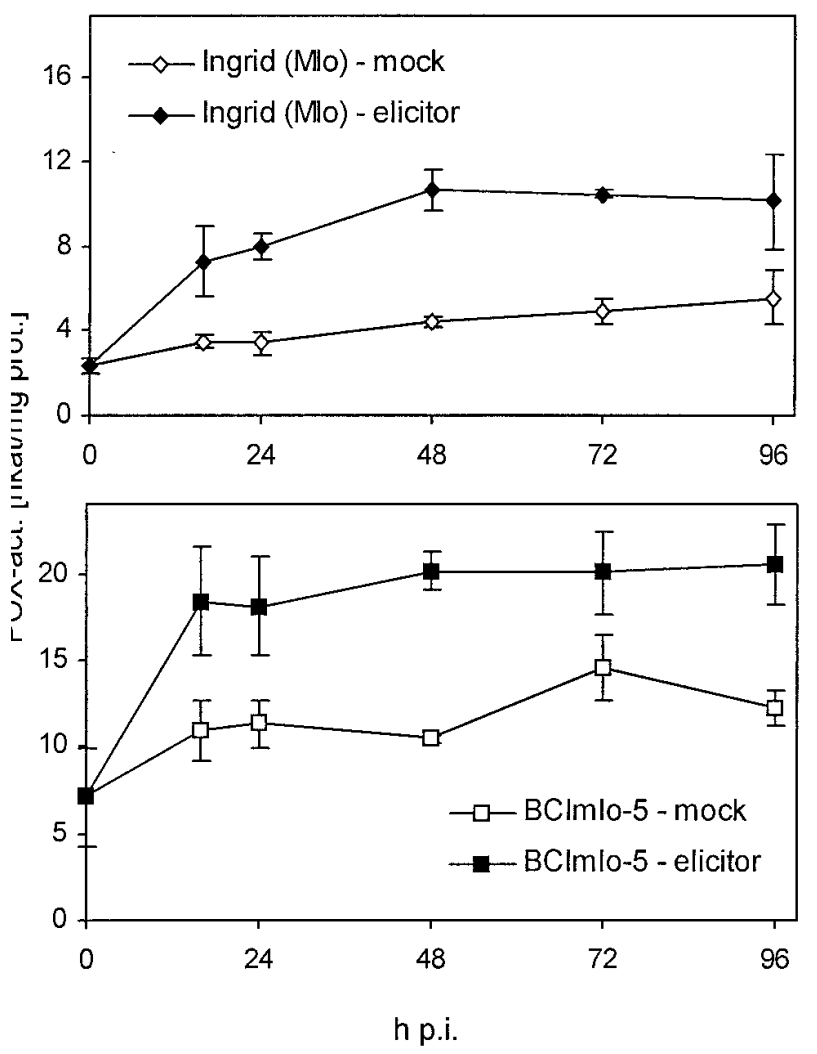

Fig. 5. Induction of peroxidase (POX) activity in barley plants of cv. Ingrid (Mlo) and a barley backcross line carrying the mlo-5 allele (BCImlo-5) of the Mlo locus. Leaves were treated by injection of an elicitor of $M$. grisea $(1 \mathrm{mg} / \mathrm{ml})$ into the intercellular spaces. Leaves were harvested at time points indicated (hours after inoculation, h p.i.). Vertical bars represent SD about the mean of three samples from a representative of two independent experiments. 
control of the HR (Dangl et al. 1996; Büschges et al. 1997). Loss of function of Mlo should prime the responsiveness of barley mlo mutants for the onset of multiple defense reactions (Büschges et al. 1997). Our data may indicate that the Mlo locus plays a complex role during infection of barley with various pathogens on the level of basic resistance, supporting the speculative role of Mlo as an evolutionary early defense trait (Wolter et al. 1993). In barley, resistance conferred by mlo mutations seems to be an exception limited to powdery mildew diseases and apparently uses a specific signal transduction pathway. This assumption is underlined by the fact that Ror genes taking part in the mlo resistance pathway do not influence the $M$. grisea phenotype on barley.

Our work provokes a critical reconsideration of the benefit of the mlo resistance in spring barley breeding programs. This is especially true for regions, like the north of Italy, the south of France, or Asia, where rice and barley might grow together. It will be of great interest to see whether rice plants carrying a mutation in Mlo-like genes are altered in blast resistance.

\section{MATERIALS AND METHODS}

Plants, pathogens, and inoculation.

The mlo- 1 allele was induced by $\mathrm{X}$-rays in the genetic background of cv. Haisa, whereas the allele mlo-3 was generated in the background of cv. Malteria Heda through X-ray mutagenesis. For generation of the mlo-5 allele, cv. Carlsberg II was chemically mutagenized with ethylmethane sulfonate (EMS) as described by Jørgensen (1983). The backcross lines in the genetic background of cv. Ingrid (BCIngrid mlo-1, BCIngrid mlo-3, BCIngrid mlo-5, BCIngrid Mlg, and BCIngrid Mla-12) were kindly provided by J. McKey (University of Uppsala, Uppsala, Sweden), whereas the barley cultivar Pallas and the mlo-5 backcross line in cv. Pallas were obtained from L. Munk (Copenhagen). The generation of the mlo-5 backcross line in cv. Pallas (BCPallas mlo-5) has been described by Kølster et al. (1986). The Ror mutant was obtained by P. Schulze-Lefert (Sainsbury Laboratory, Norwich). The mutant rorl (i.e., rorl-2, A89) was generated through EMS mutagenesis in BCIngrid mlo-5 as described in Freialdenhoven et al. (1996). Plants were grown in a growth chamber at $16^{\circ} \mathrm{C}, 60 \%$ relative humidity $(\mathrm{RH})$, and a photoperiod of $16 \mathrm{~h}$.

The $M$. grisea race 007 (H-373) was a kind gift of Y. Sekizawa (Tamagawa University, Tokyo). The fungus was cultivated on an oat-meal starch agar $\left(30 \mathrm{~g} \mathrm{liter}^{-1}\right.$ oat flakes, $20 \mathrm{~g}$ liter $^{-1}$ agar-agar, $10 \mathrm{~g} \mathrm{liter}^{-1}$ starch, and $2 \mathrm{~g} \mathrm{liter}^{-1}$ yeast extract). After incubation at $27^{\circ} \mathrm{C}$ for 2 weeks, aerial mycelia were removed with a sterile spatula and synchronous sporulation was induced by further incubation under blacklight (310 to $360 \mathrm{~nm}$ ). For inoculation the concentration of conidia was adjusted to $1 \times 10^{6} \mathrm{ml}^{-1}$ in a spraying solution $\left(1 \mathrm{~g} \mathrm{liter}^{-1}\right.$ gelatin, $0.1 \%$ Tween 20). Plants were inoculated 12 to 14 days after sowing by spraying the conidial suspension onto the leaves. After an incubation for $24 \mathrm{~h}$ in a dark moist chamber $\left(26^{\circ} \mathrm{C}\right.$, up to $\left.100 \% \mathrm{RH}\right)$, plants were kept in a humid atmosphere under the same temperature and light regime as described above.

\section{Macroscopic and microscopic analysis.}

Infection on the secondary leaves was macroscopically evaluated 7 days after inoculation. For microscopic analysis, leaves were harvested at different time points after inoculation and cleared in $0.15 \%$ (wt/vol) trichloroacetic acid in ethylalcohol/chloroform 4:1 ( $\mathrm{vol} / \mathrm{vol})$. The solution was changed once during the next $48 \mathrm{~h}$ of incubation, then leaves were rinsed in water and mounted in $50 \%$ (vol/vol) glycerol. Whole cell autofluorescence was observed by fluorescence microscopy (excitation filter $485 \mathrm{~nm}$, dichroic mirror $510 \mathrm{~nm}$, barrier filter $520 \mathrm{~nm}$; Axioplan, Zeiss, Germany). At least five seedlings were analyzed for each data point. A total of 150 infection sites were inspected per leaf and scored independently taking into account the different cell types of the adaxial epidermis (Koga et al. 1990).

\section{Elicitor treatment and measurement of POX activity.}

For elicitor treatments, a crude elicitor fraction (CEF) prepared from vegetative mycelium of $M$. grisea as described by Schaffrath et al. (1995) was used. The elicitor solution was injected into extracellular spaces of barley leaves with a Hagborg device with a hypodermic syringe (Hagborg 1970). Leaves were harvested at the time points indicated and immediately frozen in liquid nitrogen. Each sample consisted of six leaves of approximately $4 \mathrm{~cm}$ in length. After harvesting, three replicates consisting of two leaves each were ground in a mortar containing $2 \mathrm{ml}$ of phosphate buffer (50 mM, pH 5.2). The homogenate was transferred to a micro test tube and centrifuged at $13,800 \times g$ for $10 \mathrm{~min}$. The supernatant was immediately placed into a new tube and served as enzyme extract.

For determination of total POX activity a modified method of Pütter (1970) was used. The enzyme extract $(25 \mu \mathrm{l})$ was incubated with $2.875 \mathrm{ml}$ of phosphate buffer (50 mM, pH 5.2) containing $18 \mathrm{mM}$ guaiacol and the reaction was started by adding $100 \mu \mathrm{l}$ of $\mathrm{H}_{2} \mathrm{O}_{2}$ solution $(0.1 \% \mathrm{vol} / \mathrm{vol})$. Production of tetraguaiacol was measured in a spectrophotometer at $470 \mathrm{~nm}$ and enzyme activity was expressed in nkat $\mathrm{mg}^{-1}$ protein. Protein concentrations were determined with the Bio-Rad protein kit (Bio-Rad, Richmond, CA).

\section{ACKNOWLEDGMENTS}

We are grateful to P. Schulze-Lefert and A. Freialdenhoven for the Ror mutant. We thank A. J. Slusarenko for critically reading this manuscript. This work was supported in part by the Bundesministerium für Forschung, Technologie, Bildung und Wissenschaft to K.-H. K.

\section{LITERATURE CITED}

Brown, J. K. M., and Jørgensen, J. H. 1991. A catalogue of mildew resistance genes in European barley varieties. Pages 263-286 in: Integrated Control of Cereal Mildews: Virulence Patterns and Their Change. J. H. Jørgensen, ed. Risø National Laboratory, Roskilde, Denmark.

Büschges, R., Hollricher, K., Panstruga, R., Simons, G., Wolter, M., Frijters, A., van Daelen, R., van der Lee, T., Diergaarde, P., Groenendijk, J., Töpsch, S., Vos, P., Salamini, F., and Schulze-Lefert, P. 1997. The barley Mlo gene: A novel control element of plant pathogen resistance. Cell 88:695-705.

Dangl, J. L., Dietrich, R. A., and Richberg, M. H. 1996. Death don't have no mercy: Cell death programs in plant-microbe interactions. Plant Cell 8:1793-1807.

Flor, H. H. 1971. Current status of the gene for gene concept. Annu. Rev. Phytopathol. 9:275-296.

Freialdenhoven, A., Peterhänsel, C., Kurth, J., Kreuzaler, F., and Schulze-Lefert, P. 1996. Identification of genes required for the function of non-race specific mlo resistance to powdery mildew in barley. Plant Cell 8:5-14. 
Görg, R., Hollricher, K., and Schulze-Lefert, P. 1993. Functional analysis and RFLP-mediated mapping of the Mlg resistance locus in barley. Plant J. 3:857-866.

Hagborg, W. A. F. 1970. A device for injection solutions and suspensions into thin leaves of plants. Can. J. Bot. 48:1135-1136.

Hamer, J. E., Talbot, N. J., and Levy, M. 1993. Genome dynamics and pathotype evolution in the rice blast fungus. Pages 299-311 in: Advances in Molecular Genetics of Plant-Microbe Interactions. E. W. Nester and D. P. S. Verma, eds. Kluwer Academic Pub., Dordrecht, The Netherlands.

Heath, M. C., Howard, R. J., Valent, B., and Chumley, F. G. 1991. Ultrastructural interactions of one strain of Magnaporthe grisea with goosegrass and weeping lovegrass. Can. J. Bot. 70:779-787.

Jones, I. T., Sethar, H., and Davies, I. J. E. R. 1982. Genetics of partial resistance to barley mildew. Pages 449-457 in: Barley Genetics IV. Proc. Int. Barley Genet. Symp., 4th.

Jørgensen, J. H. 1983. Experience and conclusions from the work at Ris $\varnothing$ on induced mutations for powdery mildew resistance in barley. Pages 73-87 in: Induced Mutations for Disease Resistance in Crop Plants II. International Atomic Energy Agency, Vienna.

Jørgensen, J. H. 1992. Discovery, characterization and exploitation of Mlo powdery mildew resistance in barley. Euphytica 63:141-152.

Jørgensen, J. H. 1994. Genetics of powdery mildew resistance in barley. Crit. Rev. Plant Sci. 13:97-119.

Jørgensen, J. H., and Mortensen, K. 1977. Primary infection by Erysiphe graminis f. sp. hordei of barley mutants with resistance genes in the mlo locus. Phytopathology 67:678-685.

Kita, N., Toyoda, H., and Shishiyama, J. 1981. Chronological analysis of cytological responses in powdery-mildewed barley leaves. Can. J. Bot. 59:1761-1768.

Koga, H. 1994. Hypersensitive death, autofluorescence, and ultrastructural changes in cells of leaf sheaths of susceptible and resistant nearisogenic lines of rice $\left(\mathrm{Pi}-z^{t}\right)$ in relation to penetration and growth of Pyricularia oryzae. Can. J. Bot. 72:1463-1477.

Koga, H., Bushnell, W. R., and Zeyen, R. J. 1990. Specificity of cell type and timing of events associated with papilla formation and the hypersensitive reaction in leaves of Hordeum vulgare attacked by Erysiphe graminis f. sp. hordei. Can. J. Bot. 68:2344-2352.

Koga, H., Zeyen, R. J., Bushnell, W. R., and Ahlstrand, G. G. 1988. Hypersensitive cell death, autofluorescence, and insoluble silicon accumulation in barley leaf epidermal cells under attack by Erysiphe graminis f. sp. hordei. Physiol. Mol. Plant Pathol. 32:395-409.

Kogel, K. H., Beckhove, U., Dreschers, J., Münch, S., and Rommé, Y. 1994. Acquired resistance in barley. Plant Physiol. 106:1269-1277.

Kølster, P., Munk, L., Stølen, O., and Løhde, J. 1986. Near-isogenic barley lines with genes for resistance to powdery mildew. Crop Sci. 26:903-907.

Lebrun, M. H., Dutfoy, F., Gaudemer, F., Kunesch, G., and Gaudemer, A. 1990. Detection and quantification of the fungal phytotoxin tenuazonic acid produced by Pyricularia oryzae. Phytochemistry 29:3777-3783.

Lyngkjaer, M. F., Jensen, H. P., and Østergård, H. 1995. A Japanese powdery mildew isolate with exceptionally large infection efficiency on Mlo-resistant barley. Plant Pathol. 44:7786-790.

Ou, S. H. 1980. Pathogen variability and host resistance in rice blast disease. Annu. Rev. Phytopathol. 18: 167-187.

Peng, Y. L., and Shishiyama, J. 1988. Temporal sequences of cytological events in rice leaves infected with Pyricularia oryzae. Can. J. Bot. 66: 730-735.

Peterhänsel, C., Freialdenhoven, A., Kurth, J., Kolsch, R., and SchulzeLefert, P. 1997. Interaction analyses of genes required for resistance responses to powdery mildew in barley reveal distinct pathways leading to leaf cell death. Plant Cell 9:1397-1409.

Purchino, A. F., and Muchovej, J. J. 1993. Commelina agraria: A new host of Pyricularia grisea. Plant Pathol. 42:818-819.

Puitter, J. 1970. Peroxidasen. Pages 725-731 in: Methoden der enzymatischen Analyse. 3rd ed. H. U. Bergmayer, ed. Chemie, Weinheim, Germany.

Rossman, A. Y., Howard, R. J., and Valent, B. 1990. Pyricularia grisea, the correct name for the rice blast disease fungus. Mycologica 82:509512.

Schaffrath, U., Scheinpflug, H., and Reisener, H. J. 1995. An elicitor from Pyricularia oryzae induces resistance responses in rice: Isolation, characterization and physiological properties. Physiol. Mol. Plant Pathol. 46:293-307.

Sweigard, J. A., Carroll, A. M., Farrall, L., Chumley, F. G., and Valent, B. 1998. Magnaporthe grisea pathogenicity genes obtained through insertional mutagenesis. Mol. Plant-Microbe Interact. 11:404-412.

Thieron, M. 1993. Die Resistenz von Reis gegen Pyricularia oryzae. Ph.D. thesis. University of Technology, Aachen, Germany.

Umetsu, N., Kaji, J., Aoyama, K., and Tamari, K. 1974. Toxins in blast diseased rice plants. Agric. Biol. Chem. 38:1867-1874.

Valent, B., and Chumley, F. G. 1991. Molecular genetic analysis of the rice blast fungus, Magnaporthe grisea. Annu. Rev. Phytopathol. 29: 443-467.

Wiberg, A. 1974. Genetical studies of spontaneous sources of resistance to powdery mildew in barley. Hereditas 77:89-148.

Wolter, M., Hollricher, K., Salamini, F., and Schulze-Lefert, P. 1993. The mlo resistance alleles to powdery mildew infections in barley trigger a developmentally controlled defense mimic phenotype. Mol. Gen. Genet. 239:122-128. 